\title{
Comparative Effects of Interval and Continuous Aerobic Training on Haematological Variables Post-stroke - A randomized clinical trial
}

\author{
Ekechukwu E.N.D. ${ }^{1}$, Omotosho I.O. ${ }^{2}$, Hamzat T.K. ${ }^{3}$ \\ ${ }^{1}$ Department of Medical Rehabilitation, Faculty of Health Sciences and Technology, College of Medicine, University \\ of Nigeria, Enugu Campus, Enugu, Nigeria \\ ${ }^{2}$ Department of Chemical Pathology, College of Medicine, University of Ibadan, Ibadan, Nigeria \\ ${ }^{3}$ Department of Physiotherapy, Faculty of Clinical Sciences, College of Medicine, University of Ibadan, Ibadan, \\ Nigeria
}

\section{Correspondence}

Dr. I. O. Omotosho, Department of Chemical Pathology, College of Medicine, University of Ibadan, Nigeria • omotoshoio@yahoo.com

\section{SUMMARY}

Stroke induces changes in the haematological variables of post-stroke patients. Pathological changes in haematological variables can be reversed using aerobic exercise. This study assessed and compared the effects of Interval Training (IT), Continuous Training (CT) and a Combination of Interval and Continuous Training (CICT) modes of aerobic exercise on selected haematological variables of stroke survivors (SSv).

Sixty-nine consecutively recruited SSv participated in this single blind randomized controlled trial. They were randomly assigned into one of the IT $(n=25)$, CT $(n=21)$ and CICT $(n=23)$ groups. All the participants underwent aerobic training at $40-70 \%$ of heart rate reserve using a bicycle ergometer for eight consecutive weeks following the American Heart Association/American Stroke Association protocol. White blood cell count (WBC), red blood count (RBC), haemoglobin concentration $(\mathrm{Hg})$, platelet count $(\mathrm{PC})$ and mean platelet volume (MPV) were determined using PROCAN PE-6800. Data was analysed using descriptive statistics, one-way ANOVA, ANCOVA and paired t-test at $\alpha_{0.05}$.

No significant difference was observed in all the baseline variables across the three groups $(p>0.05)$. All the pre- and post-intervention haematological variables were significantly different in all the groups $(p<0.05)$ except WBC in the CT group $(\mathrm{t}=-0.538, \mathrm{p}=0.596)$. Post-intervention WBC $\left(5.71 \pm 1.31 * 10^{3} / \mu \mathrm{L} ; 6.00 \pm 1.22 * 10^{3} / \mu \mathrm{L}\right.$; $\left.5.87 \pm 1.38 * 10^{3} / \mu \mathrm{L}\right), \quad \operatorname{RBC} \quad\left(4.64 \pm 0.42^{*} 10^{6} / \mu \mathrm{L} ; \quad 4.64 \pm 0.38 * 10^{6} / \mu \mathrm{L} ; \quad 4.76 \pm 0.42^{*} 10^{6} / \mu \mathrm{L}\right)$, haemoglobin $(12.69 \pm 1.53 \mathrm{~g} / \mathrm{dL} ; \quad 11.90 \pm 1.47 \mathrm{~g} / \mathrm{dL} ; \quad 12.30 \pm 1.57 \mathrm{~g} / \mathrm{dL}), \quad$ PC $\quad\left(291.40 \pm 63.73^{*} 10^{3} / \mu \mathrm{L} ; 260.48 \pm 60.15^{*} 10^{3} / \mu \mathrm{L}\right.$; $\left.301.57 \pm 64.23^{*} 10^{3} / \mu \mathrm{L}\right)$, and MPV $(9.78 \pm 0.99 \mathrm{fl} ; 10.47 \pm 1.02 \mathrm{fl} ; 10.14 \pm 0.97 \mathrm{fl})$ were significantly different across the IT, CT and CICT groups respectively. The IT was the most effective in decreasing WBC and MPV and also the most effective in increasing $\mathrm{Hg}$ and $\mathrm{PC}$.

The IT, CT and CICT modes are effective in significantly improving the haematological variables of stroke survivors after eight weeks of aerobic training, the IT mode is, however, the most effective.

KEY WORDS: aerobic training, stroke survivors, haematological variables

\section{INTRODUCTION}

Stroke is a leading cause of disability worldwide (WHO, 2017). Post-stroke disability appears complex; low fitness and other impairments interact to drive post-stroke activity limitations and participation restriction (Saunders et al, 2014). Physical inactivity is a major modifiable risk factor 
of stroke (Tikk et al, 2014; O' Donnell et al, 2016) and also a major determinant of post- stroke disability and prognosis (Wondergem et al, 2017). There is a strong relationship between physical inactivity and abnormalities in haematological indices (Wirth et al, 2017; Daniele et al, 2018). Having a stroke has been shown to induce changes in haematological variables such as white blood cell count, red blood cell count, platelets as well as their differentials (Heikinheimo et al, 2015; Ioana, 2015; Du et al, 2016).

There is a direct association between white blood cell count and the incidence of stroke (Wu et al, 2016; Furlan et al, 2014). Elevated white blood cell count is also an independent predictor of outcomes after ischaemic stroke (Furlan et al, 2014; Heikinheimo et al, 2015) and other inflammatory disorders such as atherosclerosis, myocardial infarction and heart failure (Swirski and Nahrendorf, 2013), which are comorbidities of stroke. According to the Texas Heart Institute (2016), moderate elevation in red blood cell count can be a risk factor for stroke. A high level of red blood cell count (polycytaemia) has also been associated with poor prognosis of stroke (Ioana, 2015). Mean platelet volume and platelet count are independent risk factors of ischaemic stroke (Mayda-Domac et al, 2010). Platelet count has been observed to have changed significantly following a haemorhhagic stroke (MaydaDomac et al, 2010). Increase in mean platelet volume and decrease in platelet count have been reported as features of both acute and non-acute phases of cerebral ischaemia, which may have preceded the vascular events (Ghahremanfard et al, 2013; Du et al, 2016).

Several studies have shown that aerobic exercise can be used to improve haematological indices in cardiac patients (Sandor et al, 2014), sedentary adults (Belviranli et al, 2017; Kumar and Choudhary, 2017), athletes (Tekin et al, 2012), and young women (El-Lithy et al, 2015). A systematic review by Hamzat and Ekechukwu (2015) revealed that there is a gap in literature on the effects of aerobic training on the haematological profiles of stroke survivors and the best mode of aerobic training for improving these haematological variables. This study therefore compared the effects of three modes of aerobic exercise (interval, continuous and combined) on the haematological profiles of stroke survivors.

\section{METHOD}

\section{Participants}

A total of 69 stroke survivors participated in this study. Only stroke survivors with a diagnosis of first-time (ischaemic or haemorrhagic) unilateral stroke, with no other known neurological disorder (e.g. Parkinson's disease), were included in this study.

\section{Instruments}

The following instruments were used for data collection:

i. Fully Auto-Haematological Analyser (PROCAN PE6800, USA). This was used for the haematological analysis.

ii. Monark Bicycle Ergometer (Model AB 827E, China). This was used for the aerobic exercise training. It has a pulse rate detector as well as a timer and indicators for variables such as calories, distance covered, etc.

\section{Research Design}

The study adopted the randomized controlled trial design. Eligible participants were randomly assigned to the Continuous Training Group (CT), Interval Training Group (IT) or Combination of Continuous and Interval Training Group (CCIT) modes of aerobic exercise.

\section{Sampling}

Sample size was determined using an effect size of 0.4 , power of 0.8 for three groups and two measurements. A minimum sample size of 66 was thereafter determined. Consecutive sampling technique was used to recruit the stroke survivors.

\section{Procedure for Data Collection}

Ethical approval was sought and obtained from the Ethical Committee of the University of Port Harcourt Teaching Hospital, Port Harcourt before the commencement of the study. The trial was registered with the Pan African Clinical Trial Registry (PACTR201511001359344). The procedure was described to the participants and their informed consent obtained before participation. Willing participants were screened and those eligible were randomly assigned to one of the three training groups. Baseline measurements of the anthropometric and haematological profiles of all the participants were obtained before the commencement of the aerobic training (intervention). After eight weeks, post-test measurements of all the participants were taken.

Haematological Profile: Haematological parameters were assessed as follows:

The PROCAN PE-6800 fully auto-haematology analyser was used to analyse the sample of blood contained in an 
EDTA K3 blood collection tube. Pre-test (24 hours before training) and post-test (24 hours after training) blood samples were obtained in the morning after 12 hours fasting. The analyser uses electric resistance method for counting, haemoglobin-cyanide method and SFT method for haemoglobin. The count principle of the instrument is based on the measurement of changes in electrical resistance produced by a particle passing through an aperture sensor. The haematological parameters analysed were white blood cell count (WBC), red blood count (RBC), haemoglobin concentration, platelet count (PC) and mean platelet volume (MPV).

\section{Intervention}

The training protocol was based on the physical activity and exercise recommendations for stroke survivors by the American Heart Association - AHA (Billinger et al, 2014). This study adopted a gradual progression of intensity (40\% to $59 \%$ HRR for the first two weeks and $60 \%$ to $70 \%$ HRR for the remaining six weeks). The target heart rate was determined using the heart rate reserve method (HRR) or Karvonen formula (Karvonen et al, 1957).

\section{Target heart rate using $H R R=$ intensity (\%) $x$ (maximum HR - resting HR) + resting HR}

The 8-week exercise training programme included three training sessions per week on a stationary cycle ergometer in the gymnasium of the Department of Physiotherapy, University of Port Harcourt Teaching Hospital (UPTH), Port Harcourt. In each session, participants warmed up for a period of 5 minutes, then proceeded to the main training phase, followed by a cool down phase of 5 minutes. The duration of the training component was 20 minutes during the first 2 weeks, but was increased by 5 minutes every 2weeks.

Continuous Aerobic Training Group (CT): The aerobic training programme followed the general guidelines described above. The intensity of the exercise was set at $40-70 \%$ of heart rate reserve. This was in addition to the standard physiotherapy.

Interval Aerobic Training Group (IAT): The target workload for this group was a work intensity of $40-70 \%$ HRR (moderate/vigorous intensity) and rest/recovery at 20$29 \%$ HRR (low intensity). A work-recovery ratio of $1: 2$ minutes was chosen. The training was also in addition to their standard physiotherapy.

Combined Aerobic Training Group (CBAT): Participants were, in addition to their standard physiotherapy, trained using both interval and continuous exercise modes. For each session, interval exercise as described above was prescribed for the first half of the session while the continuous mode was prescribed for the remaining half of the session.

The participants were trained three times per week, for twenty minutes each day during the first two weeks. The training was subsequently increased by five minutes every two weeks until the eighth week. Participants in the continuous group were trained at a low intensity of 40 $59 \%$ of HRR for the first two weeks because of the deconditioning effect; the subsequent weeks' training was at a higher intensity of $60-70 \%$ of HRR. Participants in the interval group were trained at similar intensities as the continuous group but with a rest intensity of $20-29 \%$ of HRR in 1:2 minutes work/rest interval. The participants in the combined group were trained with both interval and continuous aerobic exercise at the above explained intensities.

\section{Data Analysis}

Data obtained was analysed using SPSS version 22.0. Descriptive statistics was used to summarize demographic characteristics and to present the pre-test and post-test measurements. One-way ANOVA was used to compare the baseline variables of the participants across the three training groups. ANCOVA was used to compare the effects of the three training modes on the post-intervention variables of the participants using their respective baseline variables as co-variates. Bonferroni pair-wise comparison was done as post-hoc for the ANOVA and ANCOVA tests. The level of significance was set at $\alpha=0.05$.

\section{RESULTS}

Summary of the Haematological Characteristics of the Participants

A total of 69 stroke survivors of mean age $59.33 \pm 8.80$ years participated in this study. The majority had ischaemic type of stroke $(75.4 \%)$ that occurred on the right side of the body $(59.4 \%)$. The mean white blood cell count at baseline and after the 8 weeks of training were $6.03 \pm 1.22 \times 10^{3}$ cells $/ \mu \mathrm{L}$ and $5.71 \pm 1.31 \times 10^{3}$ cells $/ \mu \mathrm{L}$ respectively for the interval training group, $5.97 \pm 1.11$ $\mathrm{x} 10^{3}$ cells $/ \mu \mathrm{L}$ and $6.00 \pm 1.22 \times 10^{3}$ cells $/ \mu \mathrm{L}$ respectively for the continuous training group, and $6.37 \pm 1.46 \times 10^{3}$ cells $/ \mu \mathrm{L}$ and $5.87 \pm 1.38 \times 10^{3}$ cells $/ \mu \mathrm{L}$ respectively for the combined training group as shown in table 1. 
Table 1. Summary of the haematological profiles of the participants at baseline and post-intervention $(\mathrm{N}=69)$

\begin{tabular}{|c|c|c|c|c|c|c|c|c|c|}
\hline \multirow{3}{*}{ Variables } & \multicolumn{3}{|c|}{ Interval Training Group $(\mathrm{n}=25)$} & \multicolumn{3}{|c|}{ Continuous Training Group $(\mathrm{n}=21)$} & \multicolumn{3}{|c|}{ Combined Training Group $(\mathrm{N}=23)$} \\
\hline & \multicolumn{2}{|c|}{ Mean \pm SD } & \multirow[b]{2}{*}{ Diff } & \multicolumn{2}{|c|}{ Mean \pm SD } & \multirow[b]{2}{*}{ Diff } & \multicolumn{2}{|c|}{ Mean \pm SD } & \multirow[b]{2}{*}{ Diff } \\
\hline & Pre & Post & & Pre & Post & & Pre & Post & \\
\hline WBC $\left(10^{3} / \mu \mathrm{L}\right)$ & $6.03 \pm 1.22$ & $5.71 \pm 1.31$ & -0.32 & $5.97 \pm 1.11$ & $6.00 \pm 1.22$ & 0.03 & $6.37 \pm 1.46$ & $5.87 \pm 1.38$ & -0.50 \\
\hline $\mathrm{RBC}\left(10^{6} / \mu \mathrm{L}\right)$ & $4.79 \pm 0.49$ & $4.64 \pm 0.49$ & -0.15 & $4.86 \pm 0.42$ & $4.64 \pm 0.38$ & -0.22 & $4.86 \pm 0.43$ & $4.76 \pm 0.42$ & -0.10 \\
\hline $\mathrm{Hgb}(\mathrm{g} / \mathrm{dL})$ & $13.02 \pm 1.56$ & $12.69 \pm 1.53$ & -0.33 & $13.30 \pm 1.44$ & $11.90 \pm 1.47$ & -1.40 & $13.09 \pm 1.58$ & $12.30 \pm 1.57$ & -0.79 \\
\hline $\mathrm{PC}\left(10^{3} / \mu \mathrm{L}\right)$ & $244.68 \pm 72.16$ & $291.40 \pm 63.73$ & 46.72 & $239.67 \pm 60.26$ & $260.48 \pm 60.15$ & 20.81 & $249.57 \pm 64.33$ & $301.57 \pm 64.23$ & 52.00 \\
\hline MPV (fl) & $10.26 \pm 1.25$ & $9.78 \pm 0.99$ & -0.48 & $10.28 \pm 1.03$ & $10.47 \pm 1.02$ & 0.20 & $10.34 \pm 0.99$ & $10.14 \pm 0.97$ & -0.20 \\
\hline
\end{tabular}

Key: Pre = Baseline, Post $=$ Post-Intervention, Diff $=$ Difference, WBC $=$ White Blood Cell Count, RBC $=$ Red Blood Cell Count, Hgb $=$ Haemoglobin, $\mathrm{PC}=$ Platelet Count, MPV $=$ Mean Platelet Volume

\section{Baseline Comparison of the Haematological Profiles of Participants across the Groups}

There was no significant difference between the mean baseline white blood cell count of the participants across the three training groups $(\mathrm{F}=0.661, \mathrm{p}=0.520)$. Also, there was no significant difference in the participants' mean baseline values of red blood cell count $(\mathrm{F}=0.187, \mathrm{p}=$ 0.830), haemoglobin concentration $(\mathrm{F}=0.198, \mathrm{p}=$ $0.821)$, platelet count $(\mathrm{F}=0.123, \mathrm{p}=0.884)$ and mean platelet volume $(\mathrm{F}=0.035, \mathrm{p}=0.966)$ across the three training groups as shown in table 2 .

\section{Comparison of the Post-Intervention Haematological Profiles of Participants across the Groups}

There was significant difference in the post-intervention white blood cell counts across the three training groups ( $\mathrm{F}$ $=17.66, \mathrm{p}<0.001)$. The comparison also showed significant differences in red blood cell count $(\mathrm{F}=6.693$, $\mathrm{p}=0.002)$, haemoglobin concentration $(\mathrm{F}=25.11, \mathrm{p}<$ $0.001)$, and platelet count $(\mathrm{F}=7.761, \mathrm{p}=0.001)$ across the three training groups. There was also significant difference in the mean platelet volumes of the participants when compared across the three training groups $(\mathrm{F}=$ 25.092, $\mathrm{p}<0.001)$. The post-hoc analysis of the significant variables showed that the participants in the continuous training group had a significantly higher postintervention white blood cell count than those in the interval training and the combined training groups. Further, the participants in the continuous training group had a significantly lower post-intervention red blood cell count than those in the combined training group. The participants in the interval training group however, had a significantly higher post-intervention haemoglobin concentration than those in the continuous training group and the combined training group. Participants in the continuous training group had a significantly lower postintervention platelet count than those in the interval training group and the combined training group but mean platelet volume was significantly lowest in the interval training group as shown in table 3 .

Difference between the baseline and the PostIntervention Haematological Profiles of Participants within the Groups

After eight weeks of aerobic training, there were significant reductions in the white blood cell counts of participants in the interval training group $(\mathrm{t}=3.927, \mathrm{p}=$ $0.001)$ and the combined training group $(\mathrm{t}=16.234, \mathrm{p}<$ $0.001)$; while there was no significant change in the white blood cell count of the participants in the continuous training group $(\mathrm{t}=-0.538, \mathrm{p}=0.596)$. There were also significant reductions in the red blood cell counts and haemoglobin concentrations within each of the interval training group $(\mathrm{t}=5.191, \mathrm{p}<0.001$ and $\mathrm{t}=7.124, \mathrm{p}<$ 0.001 respectively), the continuous training group $(\mathrm{t}=$ 8.602, $\mathrm{p}<0.001$ and $\mathrm{t}=62.894, \mathrm{p}<0.001$ respectively), and the combined training group $(\mathrm{t}=$ $60.119, \mathrm{p}<0.001$ and $\mathrm{t}=44.744, \mathrm{p}<0.001$ respectively). Also, there were significant increases in the platelet counts of the participants in the interval training group $(\mathrm{t}=-4.586, \mathrm{p}<0.001)$, the continuous training group $(\mathrm{t}=-140.312, \mathrm{p}<0.001)$, and the combined training group $(\mathrm{t}=-312.618, \mathrm{p}<0.001)$ after eight weeks. Finally, there were significant decreases in mean platelet volume within the interval training group $(\mathrm{t}=$ $4.052, \mathrm{p}<0.001)$, the continuous training group $(\mathrm{t}=-$ $41.000, \mathrm{p}<0.001)$, and the combined training group $(\mathrm{t}=$ $12.770, \mathrm{p}<0.001)$ as shown in table 4 . 
Comparative Effects of Interval and Continuous Aerobic Training on Haematological Variables Post-stroke

Table 2. Baseline comparison of the haematological profiles of participants across the groups using one-way ANOVA (N = 69)

\begin{tabular}{lllll}
\hline Variables & ITG $(\mathrm{n}=25)$ & CTG $(\mathrm{n}=21)$ & CBTG $(\mathrm{n}=23)$ & P-value \\
\hline $\mathrm{RBC}\left(10^{6} / \mu \mathrm{L}\right)$ & $4.79 \pm 0.49$ & $4.86 \pm 0.42$ & $4.86 \pm 0.43$ & 0.830 \\
$\mathrm{Hgb}(\mathrm{g} / \mathrm{dL})$ & $13.02 \pm 1.56$ & $13.30 \pm 1.44$ & $13.09 \pm 1.58$ & 0.187 \\
$\mathrm{PC}\left(10^{3} / \mu \mathrm{L}\right)$ & $244.68 \pm 72.16$ & $239.67 \pm 60.26$ & $249.57 \pm 64.33$ & 0.198 \\
$\mathrm{MPV}(\mathrm{fl})$ & $10.26 \pm 1.25$ & $10.28 \pm 1.03$ & $10.34 \pm 0.99$ & 0.123 \\
\hline
\end{tabular}

Keys: ITG = Interval Training Group, CTG = Continuous Training Group, CBTG $=$ Combined Training Group, BMI $=$ Body Mass Index, WHR $=$ WaistHip Ratio, CI = Conicity Index, AVI = Abdominal Volume Index, \% BF = Percentage Body Fat, FMI = Fat Mass Index WBC = White Blood Cell Count, $\mathrm{RBC}=$ Red Blood Cell Count, Hgb = Haemoglobin concentration, PC = Platelet Count, MPV = Mean Platelet Volume

Table 3. Comparison of the post-intervention haematological profiles of participants across the groups using ANCOVA (N $=69)$

\begin{tabular}{|c|c|c|c|c|c|}
\hline Variables & ITG $(n=25)$ & CTG (n = 21) & CBTG $(n=23)$ & F-value & P-value \\
\hline $\mathrm{WBC}\left(10^{3} / \mu \mathrm{L}\right)$ & $5.71 \pm 1.31^{\mathrm{a}}$ & $6.00 \pm 1.22^{\mathrm{b}}$ & $5.87 \pm 1.38^{\mathrm{ac}}$ & 17.660 & $<0.001^{*}$ \\
\hline $\mathrm{RBC}\left(10^{6} / \mu \mathrm{L}\right)$ & $4.64 \pm 0.49^{\mathrm{ab}}$ & $4.64 \pm 0.38^{\mathrm{a}}$ & $4.76 \pm 0.42^{\mathrm{b}}$ & 6.693 & $0.002 *$ \\
\hline $\operatorname{Hgb}(\mathrm{g} / \mathrm{dL})$ & $12.69 \pm 1.53^{\mathrm{a}}$ & $11.90 \pm 1.47^{\mathrm{b}}$ & $12.30 \pm 1.57^{\mathrm{c}}$ & 25.110 & $<0.001 *$ \\
\hline $\mathrm{PC}\left(10^{3} / \mu \mathrm{L}\right)$ & $291.40 \pm 63.73^{\mathrm{a}}$ & $260.48 \pm 60.15^{b}$ & $301.57 \pm 64.23^{\mathrm{ac}}$ & 7.761 & $0.001 *$ \\
\hline MPV (fl) & $9.78 \pm 0.99^{\mathrm{a}}$ & $10.47 \pm 1.02^{\mathrm{b}}$ & $10.14 \pm 0.97^{\mathrm{c}}$ & 25.093 & $<0.001 *$ \\
\hline
\end{tabular}

Key: ${ }^{*}=$ Significant, Items with different superscript $\left(\mathrm{X}^{\mathrm{a}}\right.$ and $\left.\mathrm{Y}^{\mathrm{b}}\right)=$ significant difference post hoc, Items with at least one same superscript $\left(\mathrm{X}^{\mathrm{a}}\right.$ and $\left.\mathrm{Y}^{\mathrm{ab}}\right)$ $=$ non-significant difference at post hoc, ITG = Interval Training Group, CTG = Continuous Training Group, CBTG = Combined Training Group, WBC

$=$ White Blood Cell Count, RBC = Red Blood Cell Count, Hgb = Haemoglobin concentration, PC = Platelet Count, MPV = Mean Platelet Volume

Table 4. Difference between the baseline and the post-intervention haematological profiles of participants within the groups using paired t-test $(\mathrm{N}=69)$

\begin{tabular}{|c|c|c|c|c|c|c|c|c|c|}
\hline \multirow[t]{2}{*}{ Variable } & \multicolumn{3}{|c|}{ Interval Training Group $(\mathrm{n}=25)$} & \multicolumn{3}{|c|}{ Continuous Training Group $(\mathrm{n}=21)$} & \multicolumn{3}{|c|}{ Combined Training Group $(\mathrm{n}=23)$} \\
\hline & Diff & t-value & $\mathrm{P}$ & Diff & t-value & $\mathrm{P}$ & Diff & t-value & $\mathrm{P}$ \\
\hline $\mathrm{WBC}\left(10^{3} / \mu \mathrm{L}\right)$ & -0.32 & 3.927 & $0.001^{*}$ & 0.03 & -0.538 & 0.596 & -0.50 & 16.234 & $<0.001 *$ \\
\hline $\mathrm{RBC}\left(10^{6} / \mu \mathrm{L}\right)$ & -0.15 & 5.191 & $<0.001 *$ & -0.22 & 8.602 & $<0.001 *$ & -0.10 & 60.119 & $<0.001 *$ \\
\hline $\mathrm{Hgb}(\mathrm{g} / \mathrm{dL})$ & -0.33 & 7.124 & $<0.001 *$ & -1.40 & 62.894 & $<0.001 *$ & -0.79 & 44.744 & $<0.001 *$ \\
\hline $\mathrm{PC}\left(10^{3} / \mu \mathrm{L}\right)$ & 46.72 & -4.586 & $<0.001 *$ & 20.81 & -140.312 & $<0.001^{*}$ & 52.00 & -312.618 & $<0.001 *$ \\
\hline MPV (fl) & -0.48 & 4.052 & $<0.001 *$ & 0.20 & -41.000 & $<0.001 *$ & -0.20 & 12.770 & $<0.001 *$ \\
\hline
\end{tabular}

\section{DISCUSSION}

There is a direct association between white blood cell count and the incidence of stroke (Wu et al, 2016; Furlan et al, 2014). Elevated white blood cell count is an independent predictor of outcomes after ischaemic stroke (Furlan et al, 2014; Heikinheimo et al, 2015) and other inflammatory disorders such as atherosclerosis, myocardial infarction and heart failure (Swirski and Nahrendorf, 2013) which are comorbidities of stroke. In this study, there were significant decreases in the white blood cell counts of participants in the combined and interval training groups while there was non-significant increase among those in the continuous training group. Also, the combined and interval modes reduced white blood cell count significantly more than the continuous mode. Similar reduction in white blood cell count after aerobic training was reported by Johannsen et al (2012) in their study, though among post menopausal women. The mechanism of exercise-induced control of leucocytosis may be explained through the actions of catecholamines, cortisol, demargination, neuronal transmitters and peptides or purine chemical transmitters (Sand et al, 2013). It is possible that high impact exercises like continuous aerobic exercise may result in lactic acid accumulation which may constitute a source of muscle 
irritation and thus proliferation of pro-inflammatory markers (leucocytosis). However, interval exercises with its period of rest may induce an anti-leucocytotic effect by regulating catecholamine and cortisol surge. It may therefore be opined that, interval aerobic training may be considered a non-phamacological anti-inflammatory modality through its anti-leucocytotic effect, especially among stroke survivors.

According to the Texas Heart Institute (2016), moderate elevation in red blood cell count can be a risk factor for stroke. A high level of red blood cell count (polycytaemia) has also been associated with poor prognosis of stroke (Ioana, 2015). In this present study, the three modes of aerobic exercise significantly reduced the red blood cell counts and haemoglobin concentrations of the participants. However, the continuous training mode appeared to have had a superior effect when compared with the other modes. This report differs from the findings of Mazoochi et al (2013) that revealed the interval training mode as having a more profound significant effect than the continuous mode on red blood cell count but nonsignificant effect on the haemoglobin concentration of Iranian athletes. The disparity in both reports may be due to differences in sample size and study population. The study by Mazoochi et al (2013) had a smaller sample size (24) and investigated athletes while this present study investigated stroke survivors. Further evidence is however needed on the comparative effects of different modes of aerobic training on the red blood cell count and haemoglobin concentration of stroke survivors.

There was significant increase in platelet count and decrease in mean platelet volume in all the treatment groups with the exception of the continuous mode that had a significant increase in mean platelet volume. The combined and interval training modes were more effective in increasing platelet count and decreasing mean platelet volume than the continuous mode. Mean platelet volume and platelet count are independent risk factors for ischaemic stroke (Mayda-Domac et al, 2010). Platelet count has been shown to be inversely correlated with haemorhhagic stroke (Mayda-Domac et al, 2010). Increase in mean platelet volume and decrease in platelet count have been reported as features of both acute and non-acute phases of cerebral ischaemia which may have preceded the vascular events (Ghahremanfard et al, 2013; Du et al, 2016) . Anti-thrombotic drugs have been shown to be useful in reducing the frequency of secondary stroke but they carry potential risk of symptomatic intracerebral haemorrhage during ischaemic stroke (Mayda-Domac et al, 2010). Therefore, in stroke management, the balance between reduction of thrombotic events and the risk of haemorrhage defines benefit (Ungerer and Münch, 2013). The significant increase in platelet count and decrease in mean platelet volume as reported in this study may therefore be of therapeutic value. The aerobic exercise induced increase in platelet count may be as a result of haemoconcentration and by platelet release from the liver, lungs, and, importantly, the spleen (Bakovic et al, 2013). Although, some studies (Scheer et al, 2011; Whittaker et al, 2013; Lippi et al, 2014) have reported an increase in mean platelet volume in response to exercise, other studies (Aldemir and Kilic, 2005; Kratz et al, 2006) appear to have reported otherwise. A systematic review with meta-analysis on the effect of aerobic exercise on mean platelet volume that would estimate the pooled effects of these studies is recommended.

A major limitation experienced in the course of this study was in the compliance of the participants especially during the first two weeks of the training, while some eligible participants were not willing to participate for fear of a repeat stroke despite the efforts to assuage this fear.

\section{CONCLUSION}

The interval, continuous and combined modes of aerobic training are effective in improving the haematological profiles of stroke survivors after eight weeks of training. However, the interval aerobic training mode is the most effective mode for improving the haematological variables of stroke survivors after eight weeks of training. The interval aerobic training mode is therefore recommended for use in stroke rehabilitation to achieve the most profound improvement of haematological variables of stroke survivors.

\section{References}

Aldemir H. and Kilic N. 2005. The effect of time of day and exercise on platelet functions and platelet-neutrophil aggregates in healthy male subjects. Molecular and Cellular Biochemistry 280(1-2): 119-124.

Bakovic D., Pivac N., Eterovic D. 2013. The effects of low-dose epinephrine infusion on spleen size, central and hepatic circulation and circulating platelets. Clinical Physiology and Functional Imaging 33(1): 30-37.

Belviranli, M., Okudan, N. and Kabak, B. 2017. The effects of acute high-intensity interval training on hematological parameters in sedentary subjects. Medical Sciences 5(3): 15 .

Billinger S.A., Arena R., Bernhardt J., Eng J.J., Franklin B.A., 
Johnson C.M., MacKay-Lyons M., Macko R.F., Mead G.E., Roth E.J., Shaughnessy M., Tang A.; on behalf of the American Heart Association Stroke Council, Council on Cardiovascular and Stroke Nursing, Council on Lifestyle and Cardiometabolic Health, Council on Epidemiology and Prevention, and Council on Clinical Cardiology. 2014. Physical activity and exercise recommendations for stroke survivors: a statement for healthcare professionals from the American Heart Association/American Stroke Association. Stroke 45: $001-023$

Daniele S., Pietrobono D., Fusi J., Iofrida C., Chico L., Petrozzi L., Gerfo A.L., Baldacci F., Galetta F., Siciliano G. and Bonuccelli U. 2018. $\alpha$-synuclein aggregates with $\beta$-amyloid or tau in human red blood cells: Correlation with antioxidant capability and physical exercise in human healthy subjects. Molecular Neurobiology 55(3): 2653-2675.

Du J., Wang Q., He B., Liu P., Chen J.-Y., Quan H. and Ma X. 2016. Association of mean platelet volume and platelet count with the development and prognosis of ischemic and hemorrhagic stroke. Int. Jnl. Lab. Hem. 38: 233-239. doi:10.1111/ijlh.12474

El-Lithy A., El-Mazny A., Sabbour A. and El-Deeb A. 2015. Effect of aerobic exercise on premenstrual symptoms, haematological and hormonal parameters in young women. Journal of Obstetrics and Gynaecology 35(4): 389-392.

Furlan J.C., Vergouwen M.D., Fang J., Silver F.L. 2014. White blood cell count is an independent predictor of outcomes after acute ischaemic stroke. Eur J Neurol 21(2): 215-22.

Ghahremanfard F., Asghari N., Ghorbani R., Samaei A., Ghomi H. and Tamadon M. 2013. The relationship between mean platelet volume and severity of acute ischemic brain stroke. Neurosciences pp.147-151.

Hamzat T.K. and Ekechukwu N.E. 2015. Aerobic exercise training in stroke rehabilitation: Any gap in knowledge. Nigerian Journal of Medical Rehabilitation 18(1).

Heikinheimo T., Putaala J., Haapaniemi E., Kaste M. and Tatlisumak T. 2015. Leucocyte count in young adults with first ever ischaemic stroke: Associated factors and association on prognosis. International Journal of Stroke 10(2): 245-250.

Ioana Mozos. 2015. Mechanisms linking red blood cell disorders and cardiovascular diseases. BioMed Research International. doi:10.1155/2015/682054.

Johannsen N.M., Swift D.L., Johnson W.D., Dixit V.D., Earnest C.P., Blair S.N. 2012. Effect of different doses of aerobic exercise on total white blood cell (WBC) and WBC subfraction number in postmenopausal women: Results from DREW. PLoS ONE 7(2): e31319.

Karvonen M.J., Kentala E. and Mustala O. 1957. The effects of training on heart rate: A longitudinal study. Annales Medicine Experimentalis et Biologiae Fenniae 38(3): 307-315.

Kratz A., Wood M.J., Siegel A.J., Hiers J.R., and van Cott E.M. 2006. Effects of marathon running on platelet activation markers: direct evidence for in vivo platelet activation. American Journal of Clinical Pathology 125(2): 296-300.
Kumar S. and Choudhary S. 2017. Investigation of the effects of aerobic exercise programs on hematological parameters of sedentary people. World Academy of Science, Engineering and Technology, International Journal of Sport and Health Sciences 4(1).

Lippi G., Salvagno G.L., Danese E., Tarperi C., Guidi G.C. and Schena F. 2014. Variation of red blood cell distribution width and mean platelet volume after moderate endurance exercise. Advances in Hematology Article ID 192173, 4 pages

Mayda-Domaç F., Misirli H., Yilmaz M. 2010. Prognostic role of mean platelet volume and platelet count in ischemic and hemorrhagic stroke. J Stroke Cerebrovasc Dis 19(1): 66-72.

Mazoochi M., Fateminezhad S.E. and Mazoochi T. 2013. Effects of continuous and interval training on different fitness parameters in athletes. World Applied Sciences Journal 28(3): 312-315.

O'Donnell M.J., Chin S.L., Rangarajan S., Xavier D., Liu L., Zhang H., Rao-Melacini P., Zhang X., Pais P., Agapay S. and Lopez-Jaramillo P. 2016. Global and regional effects of potentially modifiable risk factors associated with acute stroke in 32 countries (INTERSTROKE): A case-control study. The Lancet 388(10046): 761-775.

Sand K.L., Flatebo T., Andersen M.B. and Maghazachi A.A. 2013. Effects of exercise on leukocytosis and blood hemostasis in 800 healthy young females and males. World Journal of Experimental Medicine 3(1): 11-20.

Sandor B., Nagy A., Toth A., Rabai M., Mezey B., Csatho A., Czuriga I., Toth K. and Szabados E. 2014. Effects of moderate aerobic exercise training on hemorheological and laboratory parameters in ischemic heart disease patients. PloS One 9(10): p.e110751.

Saunders D.H., Greig C.A. and Mead G.E. 2014. Physical activity and exercise after stroke. Stroke 45(12): 3742-3747.

Scheer F.A., Michelson A.D. and Frelinger A.L. 2011. The human endogenous circadian system causes greatest platelet activation during the biological morning independent of behaviors. PLoS One 6(9). Article ID e24549, 2011.

Swirski F.K. and Nahrendorf M., 2013. Leukocyte behavior in atherosclerosis, myocardial infarction, and heart failure. Science, 339(6116), pp.161-166.

Tekin A., Aaraymen R., Gouml K. and Eliouml M. 2012. The effect of acute exercises on blood hematological parameters in handball players. African Journal of Microbiology Research 6(9): 2027-2032.

Texas Heart Institute. 2016. Stroke Risk Factors. http://www.texasheart.org/HIC/ Topics/Cond/strokris.cfm. Assessed 10/12/16

Tikk K., Sookthai D., Monni S., Gross M.L., Lichy C., Kloss M. and Kaaks R. 2014. Primary preventive potential for stroke by avoidance of major lifestyle risk factors. Stroke. STROKEAHA-114.

Ungerer M. and Münch G. 2013. Novel antiplatelet drugs in clinical development. Thromb Haemost 110(5): 868-875. 
Whittaker J.P., Linden M.D. and Coffey V.G. 2013. Effect of aerobic interval training and caffeine on blood platelet function. Medicine \& Science in Sports \& Exercise 45(2): 342-350.

Wirth K., Klenk J., Brefka S., Dallmeier D., Faehling, K., Figuls M.R., Tully M.A., Giné-Garriga M., Caserotti P., Salvà A. and Rothenbacher D. 2017. Biomarkers associated with sedentary behaviour in older adults: A systematic review. Ageing Research Reviews 35: 87-111.

Wondergem R., Pisters M.F., Wouters E.J., Olthof N., de Bie R.A., Visser-Meily J.M. and Veenhof C. 2017. The course of activities in daily living: Who is at risk for decline after first ever stroke? Cerebrovascular Diseases 43(1-2): 1-8.

World Health Organization. 2017. Cardiovascular disease http://www.who.int/ cardiovasculardiseases/ resources/atlas/en/ (accessed on 2017-06-29 at 19:20)

Wu C.Y., Yeh T.T., Lee Y.Y., Teng C.H. and Chang K.C. 2016. Synergistic effects of aerobic exercise and cognitive training on cognition and quality of life in stroke patients with cognitive decline. Archives of Physical Medicine and Rehabilitation 97(10): 12 . 